\title{
Yellow Mangifera indica Linn. and Artocarpus heterophyllus Lam. seed starch as binder and disintegrant in paracetamol tablet formulation
}

\author{
Richelle Ann M. Manalo ${ }^{1 *}$, Erna C. Arollado ${ }^{1,2}$, Joriza Mae M. Pellazar', Mae Pauline F. Siocson', Romeo-Luis F. Ramirez' \\ ${ }^{1}$ Institute of Pharmaceutical Sciences-National Institutes of Health, University of the Philippines Manila, Ermita, Manila, 1000 Philippines. \\ ${ }^{2}$ Department of Pharmacy, College of Pharmacy, University of the Philippines Manila, Ermita, Manila 1000 Philippines.
}

\begin{tabular}{|c|c|}
\hline ARTICLE INFO & ABSTRACT \\
\hline $\begin{array}{l}\text { Article history: } \\
\text { Received on: } 27 / 09 / 2017 \\
\text { Accepted on: 15/12/2017 } \\
\text { Available online: } 30 / 03 / 2018\end{array}$ & $\begin{array}{l}\text { Utilization of fruit by-products offers a potential solution in minimizing the economic and environmental problems } \\
\text { posed by these wastes. In this study, the seeds of yellow Mangifera indica Linn. and Artocarpus heterophyllus Lam. } \\
\text { were used as sources of starch as binder and disintegrant in the formulation of paracetamol tablets. Physicochemical, } \\
\text { binder and disintegrant properties of the isolated starches were measured and evaluated based on the United States } \\
\text { Pharmacopeia (USP) specifications. The } M \text {. indica and } A \text {. heterophyllus seed starches were white to off-white in color, }\end{array}$ \\
\hline $\begin{array}{l}\text { Key words: } \\
\text { Mangifera indica, } \\
\text { Artocarpus heterophyllus, } \\
\text { yellow mango, jackfruit, } \\
\text { seeds, binder, disintegrant, } \\
\text { paracetamol. }\end{array}$ & $\begin{array}{l}\text { odorless, and fine in texture, with starch yields of } 25.64 \% \text { and } 44.85 \% \text {, respectively. The } M \text {. indica has elongated } \\
\text { shape while } A \text {. heterophyllus has smaller round granules, resulting in passable to poor flowability. The lower solubility } \\
\text { ( } \mathrm{p}<0.001 \text { ), and higher swelling power ( } \mathrm{p}=0.017 \text { ) and viscosity }(\mathrm{p}<0.001) \text { of } M \text {. indica may also be due to its } \\
\text { larger, rod-shaped granules relative to A. heterophyllus. The isolated starches conformed to the USP specifications } \\
\text { of identification, loss on drying, } \mathrm{pH} \text { and limit of iron of official starches. Furthermore, both displayed acceptable } \\
\text { average tablet weight, thickness, hardness, friability, disintegration time, dissolution and potency when used as binder } \\
\text { and disintegrant in tablet formulation based on the USP acetaminophen (paracetamol) monograph. In conclusion, the } \\
\text { starch isolated from yellow } M \text {. indica and } A \text {. heterophyllus seeds met the acceptance criteria of the physicochemical } \\
\text { tests for starch and quality control tests for the USP acetaminophen (paracetamol) tablets. Hence, they can be used as } \\
\text { economical and alternative sources of starch for pharmaceutical use. }\end{array}$ \\
\hline
\end{tabular}

\section{INTRODUCTION}

Philippines is within the top 10 fruit-producing countries in the world in 2010-2011, contributing to $2.70 \%$ of the total world fruit production (Pathak et al., 2015). Mangifera indica Linn. (Anacardiaceae) or mango, and Artocarpus heterophyllus Lam. (Moraceae) or jackfruit, are major fruit crops in the country, with 885,000 and 44,605 metric ton production in 2014, respectively (Philippine Statistics Authority, 2015). These fruits have been used mainly in food industry and their pulp can be eaten raw, preserved or dried. Exportation of these fruits has also increased, as observed in the proliferation of dried products, candies and purees in the market. The huge utilization

\section{${ }^{*}$ Corresponding Author}

Richelle Ann M. Manalo, Institute of Pharmaceutical Sciences-National Institutes of Health, University of the Philippines Manila, Ermita, Manila, 1000 Philippines.E-mail:rmmanalo4@up.edu.ph of these fruits resulted in waste generation of approximately 6.0\% their total production in 2014 (Philippine Statistics Office, 2015). These wastes were generated from the seeds during food processing and consumption. Thus, utilization of these seeds will significantly reduce the pollution load and may result in increased commercial value of the wastes.

Previous studies have reported the appreciable quantities of starch in the seeds of M. indica (El Saadany et al., 1980) and A. heterophyllus (Tulyathan et al., 2002). Starch is known to be one of the utilized excipients in tablet formulation because it is readily obtained from natural sources. It acts as binder, lubricant, disintegrant and diluent in various solid dosage forms (Hartesi et al., 2016; Ohubiojo and Rodrigues, 2012). Starch has also been explored in several pharmaceutical applications such as in nasal (Illum et al., 2001), periodontal (Bromberg et al., 2001), nanoparticles (Ahmad et al., 2012) and film-based (Krogars et al., 2002) drug delivery systems. Common sources of starch in Asia include potato, corn, cassava, wheat and tapioca (Fuglie, 1998). 
However, these produce are also used as food, which compete with their pharmaceutical applications. Hence, interests on the search of novel sources of starch have been increasing.

In this study, the physicochemical, binder and disintegrant properties of starch from yellow $M$. indica and A. heterophyllus seeds were assessed to determine their potential as sources of pharmaceutical starch in the formulation of paracetamol tablets.

\section{MATERIALS AND METHODS}

\section{Sample collection}

Yellow $M$. indica and A. heterophyllus were collected from the local wet markets in the Manila, Philippines. The fruits were submitted to the Botany Division of the National Museum Philippines, and were given voucher specimen numbers 16-04391-07 and 01, respectively.

\section{Starch extraction}

The method was based on Rajeevkumar et al. (2010) with some modifications. The seeds were washed thoroughly with water followed by removal of extraneous parts. The collected seeds were dried, cut into small pieces, weighed and soaked in $0.1 \%$ sodium metabisulfite solution for $24 \mathrm{~h}$. The solutions were filtered with cheesecloth and the residues were soaked in hot $80 \%$ ethanol solution overnight. The soaked residues were homogenized by grinding in a regular blender at low speed to produce a smooth paste. The pastes were stirred, allowed to settle and decanted to remove the supernatant liquid. The residues were treated with 0.1 $\mathrm{M} \mathrm{NaOH}$ with volume equivalent to five times the weight of the sample and left for $18 \mathrm{~h}$ at room temperature, with intermittent shaking. The supernatants and any brown surface layers were removed, and the residues were first washed with $0.1 \mathrm{M} \mathrm{HCl}$ and then repeatedly using distilled water until they become white. The residues were filtered under vacuum to remove residual water and dried in an oven at $60^{\circ} \mathrm{C}$ until completely dried. The dried powders were crushed, passed through a $100-\mathrm{mm}$ sieve mesh and stored in airtight plastic containers at $4^{\circ} \mathrm{C}$ until analyzed.

\section{Organoleptic characteristics}

Six assessors were selected to evaluate the organoleptic characteristics using sensory evaluations of the following parameters: texture, odor, and color.

\section{Density measurements}

The procedure for bulk density was based on the United States Pharmacopeia (USP) (2017). A 25-g sample was placed in a dry $100-\mathrm{mL}$ graduated cylinder and the initial volume was noted. The graduated cylinder was tapped to a constant volume. The bulk and tapped densities were calculated using the formulas below:

$$
\begin{aligned}
& \text { Bulk density, } \mathrm{g} / \mathrm{mL}=\frac{\text { Weight of sample }}{\text { Initial volume }} \\
& \text { Tapped density, } \mathrm{g} / \mathrm{mL}=\frac{\text { Weight of starch }}{\text { Tapped volume }}
\end{aligned}
$$

The compressibility index (CI) and Hausner ratio (HR) were also computed using the results of bulk and tapped densities.

$$
\begin{aligned}
\mathrm{CI} & =\frac{\text { (Tapped density }- \text { bulk density) }}{\text { Tapped density }} \times 100 \\
\mathrm{HR} & =\frac{\text { Tapped density }}{\text { Bulk density }}
\end{aligned}
$$

\section{Angle of Repose}

The angle of repose was measured using the method of the USP (2017) with some modifications. A powder funnel was clamped with its tip $2 \mathrm{~cm}$ above a clean white paper. The sample was allowed to flow through the funnel until the apex of the powder cone just touched the tip of the funnel. The angle of repose was determined by measuring the height and base of the powder cone using the formula below:

$$
\tan \propto=\frac{\text { height of the cone of powder }}{0.5 \times \text { base }}
$$

\section{Morphology}

The morphology was investigated using scanning electron microscope (Jeol JSM 5120, USA). The samples were plated with gold using sputter coater and examined under the microscope, with an accelerating voltage of $15 \mathrm{~kW}$ and magnification of 1000, 3500 and 5000x. The size of the granules was determined by random selection of granule diameters in the micrographs.

\section{Amylose-amylopectin ratio}

Amylose and amylopectin were determined using the method of Wang et al. (2010) with slight modifications. The samples were defatted for $7 \mathrm{~h}$ using hexane prior to the conduct of analysis. A 10-mg sample was weighed and added with $3 \mathrm{~mL}$ $1 \mathrm{M} \mathrm{NaOH}$. The solution was mixed, placed in a water bath set at $60^{\circ} \mathrm{C}$ for $5 \mathrm{~min}$, and sonicated for $25 \mathrm{~min}$. The sample was then neutralized with $1 \mathrm{M} \mathrm{HCl}$ and diluted to $10 \mathrm{~mL}$ with distilled water. An aliquot of $200 \mathrm{uL}$ sample was transferred to a glass tube, added with $200 \mu \mathrm{L}$ distilled water and $1600 \mu \mathrm{L}$ iodine solution. The solution was mixed and then left in the dark for $30 \mathrm{~min}$ for color development. The absorbance was read at 535, 620 and 730 $\mathrm{nm}$ for amylose, and 466, 535 and $650 \mathrm{~nm}$ for amylopectin using UV-Vis spectrophotometer (Hitachi UH5300, Japan).

\section{Swelling power and solubility}

Swelling power and solubility characteristics were determined using the method of Walter et al. (2000) with some modifications. A 0.1-g sample was weighed in a tube, and the sum of the weight of tube and sample was recorded. One percent starch solution was prepared and heated from 50 to $95^{\circ} \mathrm{C}$, at every $5 \mathrm{~min}$ interval, in a waterbath for $30 \mathrm{~min}$ with constant agitation. The slurry was centrifuged at $3200 \mathrm{rpm}$ for $10 \mathrm{~min}$. The supernatant was removed, transferred to a pre-weighed aluminum dish and dried to constant weight in oven at $100^{\circ} \mathrm{C}$ for $4 \mathrm{~h}$. Solubility was calculated using the formula below. The weight of the wet sediment in tube was recorded and the swelling power was also calculated. 


$$
\begin{gathered}
\% \text { Solubility }=\frac{\text { Weight }_{\text {solid content of supernatant }}}{\text { Weight }_{\text {starch sample }}} \times 100 \\
\text { Swelling power, } \mathrm{g} / \mathrm{g}=\frac{\text { Weight }_{\text {wet sediment in tube }- \text { Weight }_{\text {starch sample in tube }}}}{\text { Weight }_{\text {starch sample }}}
\end{gathered}
$$

Viscosity of the samples was also evaluated using Brookfield digital viscometer (LVT Brookfield viscometer, USA) following the method of de Oliveira et al. (2011). Starch slurries were made by preparing $5 \% \mathrm{w} / \mathrm{v}$ with distilled water, heated to $80^{\circ} \mathrm{C}$, maintained for $10 \mathrm{~min}$ and cooled for $30 \mathrm{~min}$. The final viscosities were measured using spindle 2 at $60 \mathrm{rpm}$ and reported as centipoise, $\mathrm{cP}(1 \mathrm{mPa} \cdot \mathrm{s})$ at room temperature.

\section{USP Specifications}

Identification test for starch was based on the USP (2017). A $0.2-\mathrm{mg}$ sample was diluted in $10 \mathrm{~mL}$ water. The solution was boiled for $1 \mathrm{~min}$ and cooled. A 1-mL mucilage was transferred to another tube and added with $0.5 \mathrm{~mL}$ of iodine and potassium iodide solution. The presence of orange-red to dark blue color, which disappears upon heating, is indicative of a positive result.

The procedure for loss on drying (LOD) was based on the USP (2017) with some modifications. One-gram sample was placed in a weighing dish previously dried under the conditions prescribed for the sample to be examined. The starch was dried at $130^{\circ} \mathrm{C} \pm 2^{\circ} \mathrm{C}$ for $1.5 \mathrm{~h}$. The weighing dish with sample was placed in a desiccator for $30 \mathrm{~min}$ to cool and weighed. LOD was calculated based on the formula below:

$$
\% \text { LOD }=\frac{\text { Weight }_{\text {initial (dish }+ \text { sample) }}-\text { Weight }_{\text {final (dish }+ \text { sample })}}{\text { Weight }_{\text {sample }}} \times 100
$$

The $\mathrm{pH}$ measurement was conducted following the method of the USP (2017). A slurry was prepared by weighing 5 $\mathrm{g}$ starch sample and adding $25 \mathrm{~mL}$ of freshly boiled water. The solution was agitated continuously at a moderate rate for $1 \mathrm{~min}$. The solution was allowed to stand for $15 \mathrm{~min}$ and the $\mathrm{pH}$ was determined using a pH meter (Trans BP3001, Singapore).

The determination of limit of iron was based on the procedure of USP (2017) under the corn starch monograph. A 1.5-g starch sample was mixed with $15 \mathrm{~mL} 2 \mathrm{~N} \mathrm{HCl}$ and filtered. A $10-\mathrm{mL}$ filtrate was transferred to a test tube followed by the addition of $2 \mathrm{~mL}$ citric acid solution $(2: 10)$ and $0.1 \mathrm{~mL}$ thioglycolic acid. The solution was made alkaline by the addition of $10 \mathrm{~N}$ ammonium hydroxide followed by dilution with water to $20 \mathrm{~mL}$. The sample solution was observed for the intensity of pink color change after $5 \mathrm{~min}$.

\section{Paracetamol tablet preparation}

Wet granulation method was employed in preparing $500 \mathrm{mg}$ paracetamol tablet batches. The percentage composition of the tablet batch is shown in Table 1. Paracetamol and starch were screened separately through sieve no. 40. The starch binder paste was prepared by dispersing starch in $9 \mathrm{~mL}$ water followed by addition of $24 \mathrm{~mL}$ boiling water. The solution was stirred until a paste was formed. The weighed paracetamol and starch were mixed, and the starch paste was incorporated thoroughly. The moistened mass, formed into balls, were passed through mesh screen no. 4 . The granules were spread on trays and placed in drying oven set at $65^{\circ} \mathrm{C}$ for $50 \mathrm{~min}$. The granules were then passed through sieve nos. 20 and 40. The good granules and fine granules (10\% of the weights of good granules) were combined. Magnesium stearate, which was previously passed through sieve no. 8, was used as lubricant and added to the combined granules and mixed. The granules were compressed into tablets using 7/16" concave punches (Stokes, Pennsylvania).

Table 1: Composition of $500 \mathrm{mg}$ Paracetamol tablet batch.

\begin{tabular}{lc}
\hline Ingredient & Percentage, $\mathbf{\%} \mathbf{w} \mathbf{w}$ \\
\hline Paracetamol & 81.08 \\
Starch $^{\mathrm{a}}$ & 2.58 \\
Starch $^{\mathrm{b}}$ & 15.11 \\
Magnesium stearate & 1.23 \\
\hline
\end{tabular}

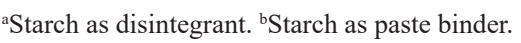

\section{Evaluation of paracetamol tablet batches}

In order to assess the quality and performance of the paracetamol tablet batches, quality control tests were conducted based on the USP (2017) for paracetamol tablets. These tests include uniformity of weight, thickness, hardness, friability, disintegration, dissolution and assay.

\section{Statistical analysis}

All the physicochemical and quality control tests were performed in triplicate, except for uniformity of weight, thickness, and hardness, and dissolution, which were conducted in 10 and 6 trials, respectively. The data generated were reported as mean \pm standard deviation (SD) and analyzed by independent t-test to compare the differences between starch samples using Statistical Package for Social Sciences (SPSS) 23.0 software. Probabilities, $\mathrm{p}$, were considered statistically significant when $p<0.05$.

\section{RESULTS AND DISCUSSION}

The starch from yellow M. indica yielded $25.64 \mathrm{~g}$ per 100 g seeds, which is similar to the yield obtained from earlier literature (El Saadany et al., 1980). The starch from A. heterophyllus had a lower yield of $44.85 \mathrm{~g}$ per $100 \mathrm{~g}$ seeds compared to previous study (Tulyathan et al., 2002) due to differences in the extraction method. The isolated starches displayed comparable organoleptic characteristics with official starches, which were white to offwhite in color, odorless and fine in texture. This demonstrates that the isolated starches were acceptable in terms of organoleptic characteristics.

The physicochemical properties of the starch obtained from yellow $M$. indica and $A$. heterophyllus seeds are shown in Table 2.

Powder flow is an important criterion in the manufacture of solid dosage forms, particularly in the functionality of excipient for direct compression, and in the determination of weight, hardness, and content uniformity of tablets (Achor et al., 2015; Shah et al., 2008). CI, HR and angle of repose are indirect methods used to determine the flow properties of powders. Particularly, $\mathrm{CI}$ is a measure of powder bridge strength and stability, HR is related to interparticulate friction (Shah et al., 2008) and angle of repose measures interparticulate cohesion. CI of $1-10 \%$ or HR 
of $1.00-1.11$ can be described as excellent, $11-15 \%$ or $1.12-1.18$ as good, $16-20 \%$ or $1.19-1.25$ as fair, $21-25 \%$ or $1.26-1.34$ as passable, $26-31 \%$ or $1.35-1.45$ as poor and $>32 \%$ or $1.46-1.59$ as very poor, in terms of flow properties (Aulton, 2017). For angle of repose, a $25-30^{\circ}$ is indicative of excellent flow properties, $31-35^{\circ}$ as good, $36-40^{\circ}$ as fair, $41-45^{\circ}$ as passable, $46-55^{\circ}$ as poor and $>56^{\circ}$ as very poor (USP, 2017). Based on these criteria, the starch from yellow $M$. indica and A. heterophyllus seeds showed poor and very poor flow properties, respectively, on both CI and HR $(p<0.001)$. However, they displayed passable flow property and comparable results on angle of repose $(p=0.103)$. Disparity in the flow property results between CI and HR, and angle of repose may be caused by the qualitativeness of the measurements and their scaling (Shah et al., 2008).
Table 2: Physicochemical properties of the starch from yellow $M$. indica and $A$. heterophyllus seeds.

\begin{tabular}{lcc}
\hline Parameter & $\begin{array}{c}\text { Yellow } \text { M. } \text { indica seed } \\
\text { starch }\end{array}$ & $\begin{array}{c}\text { A. heterophyllus seed } \\
\text { starch }\end{array}$ \\
\hline Bulk density, g/mL & $0.28 \pm 0.016$ & $0.35 \pm 0.002$ \\
Tapped density, g/mL & $0.40 \pm 0.017$ & $0.56 \pm 0.01$ \\
CI, \% & $29.54 \pm 1.14^{*}$ & $37.90 \pm 0.79$ \\
HR & $1.42 \pm 0.023^{*}$ & $1.61 \pm 0.020$ \\
Angle of repose, & & $42.50 \pm 1.00$ \\
Amylose/amylopectin & $15.59 \pm 1.49 * / 76.39 \pm 3.34$ & $23.36 \pm 3.96 / 69.16 \pm 4.01$ \\
ratio, \% & $15.71 \pm 0.84 *$ & $12.02 \pm 1.40$ \\
Swelling power, g/g & $7.19 \pm 0.44^{*}$ & $13.96 \pm 0.77$ \\
Solubility, \% & $1590.00 \pm 151.33^{*}$ & $428.33 \pm 65.21$ \\
Final viscosity, cP & & \\
\hline
\end{tabular}

*Significant difference $(p<0.05)$ between starch samples. CI - Compressibility index, HR - Hausner ratio.
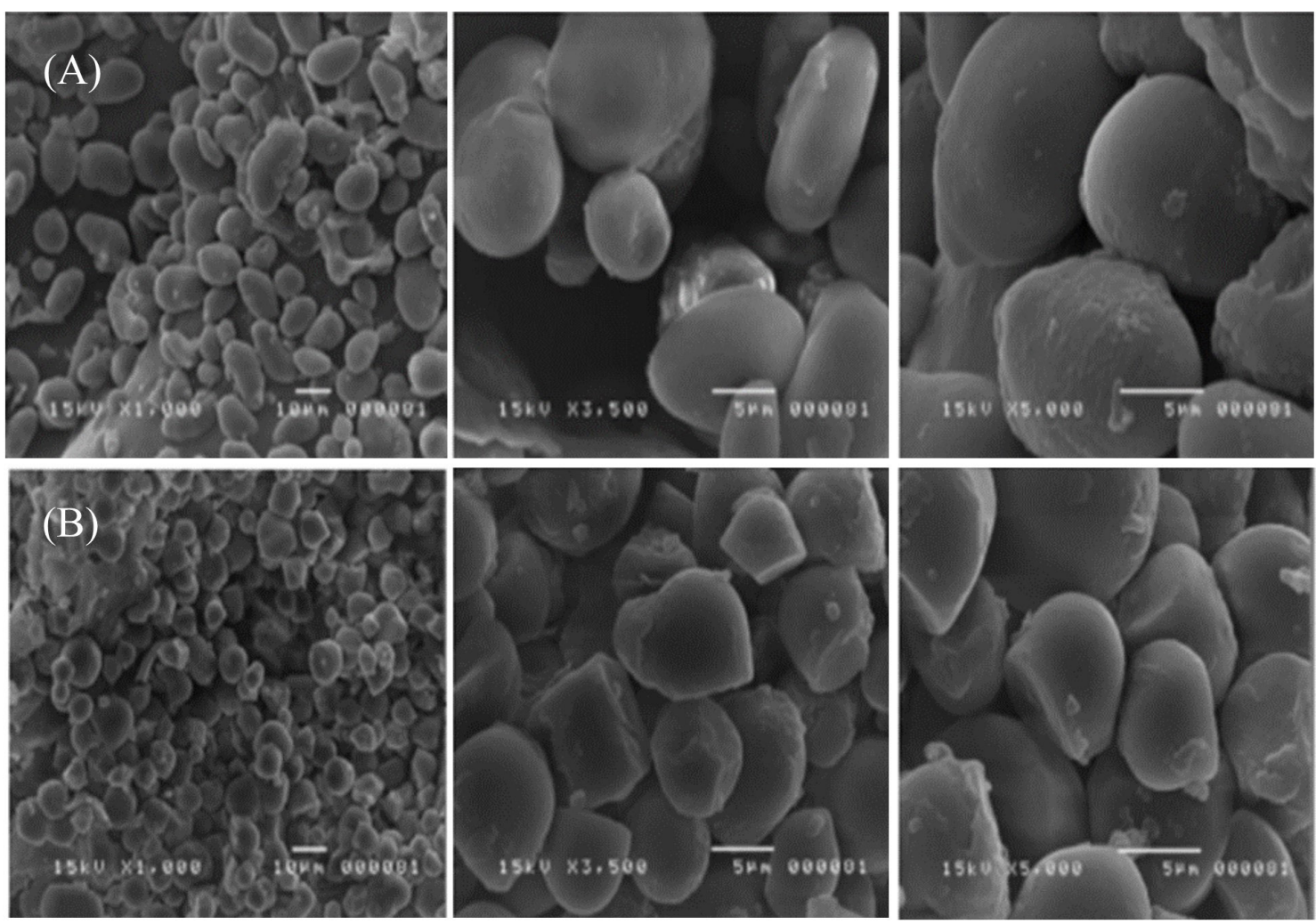

Fig. 1: Scanning electron micrographs of starch isolated from (A) yellow $M$. indica seeds and (B) jackfruit seeds.

The poor powder flowability of the starch isolated from yellow M. indica and A. heterophyllus seeds may be attributed to their distinct morphological features, with regards to size and shape. Both the granules of yellow $M$. indica (Figure 1A) and A. heterophyllus (Figure 1B) seed starches have slightly smooth surface, with sizes ranging from 7-20 $\mu \mathrm{m}$ classified under small to medium granules (Builders and Arhewoh, 2016). The yellow $M$. indica seed starch has elongated granules while $A$. heterophyllus has smaller round granules. Irregular, rod-shaped granules and small particle size have been reported to decrease bulk density, leading to poorer flowability (Lahdenpää et al., 1996). This is caused by strong interparticle interaction that results to interlocking. In turn, this leads to formation of arches, cakes and ratholes (Seville et al., 1997).

Two important constituents of starch are amylose and amylopectin. Both of these polymers are composed of D-glucose units, with the straight-chain amylose exhibiting $\alpha(1 \rightarrow 4)$ linkages and the branched amylopectin containing $\alpha(1 \rightarrow 4)$ and $\alpha(1 \rightarrow 6)$ linkages. Determination of both polysaccharides is important as they affect the functionality of starch as excipients (Builders 
and Arhewoh, 2016). The starch from yellow $M$. indica seeds demonstrated significantly lower amylose content $(p=0.033)$ relative to $A$. heterophyllus seed starch. The value of amylose obtained from both starches were similar to those reported on previous literatures (Hassan et al., 2013; Tulyathan et al., 2002). However, amylopectin content of both starches displayed comparable results $(p=0.074)$. It is noted that the sum of amylose and amylopectin contents of the starch samples was not equal to $100 \%$. This observation is in accordance with the study of Wang et al. (2010) that the commonly used formula for amylopectin content, which is $100 \%$ less \% amylose content, corresponds to the theoretical but not the actual amylopectin content.

Solubility, swelling power and viscosity are parameters that contribute to disintegrant and paste characteristics of starch. Starch granules start to absorb water and swell upon application of heat. Further increase in temperature leads to swelling and solubility. As maximum swelling is achieved, disintegration of swollen granules occurs, resulting to changes in viscosity (Builders et al., 2010). The starch obtained from the yellow $M$. indica seeds displayed significantly lower solubility $(p<0.001)$ but significantly higher swelling power $(p=0.017)$ and final viscosity $(p<0.001)$ compared to A. heterophyllus seeds. This corroborated with earlier studies that higher swelling power and lower solubility may be due to irregular shape and large granule size of starches (Singh et al., 2003). The larger, irregular, rodshaped granules of yellow $M$. indica seed starch relative to $A$. heterophyllus seed starch aid in reducing the mobility of the starch, even at high swelling capacity, leading to lower solubility values. Previous studies have also reported the direct association of amylopectin content with swelling capacity. Amylopectin, due to its highly branched structure, takes up water easily resulting to increased swelling, while amylose has been reported to restrict initial swelling (Lin et al., 2015; Singh et al., 2003). The negative correlation between the amylose content and final viscosity has been attributed to the strong molecular interaction of amylose molecules and their ability to complex with lipids (Singh et al., 2003), which inhibits the development of viscosity (Tziotis et al., 2005).

Table 3: Physicochemical properties of the starch from yellow $M$. indica seeds and $A$. heterophyllus based on the USP specifications for potato, wheat, tapioca, rice and corn starch.

\begin{tabular}{lccc}
\hline Parameter & $\begin{array}{c}\text { Yellow } \text { M. } \text { indica } \\
\text { seed starch }\end{array}$ & $\begin{array}{c}\text { A. heterophyllus } \\
\text { seed starch }\end{array}$ & USP specifications \\
\hline Identification & Conforms & Conforms & $\begin{array}{c}\text { Orange-red to dark } \\
\text { blue color }\end{array}$ \\
$\begin{array}{l}\text { Loss on drying } \\
\text { (LOD), } \%\end{array}$ & $7.33 \pm 0.68$ & $8.05 \pm 0.14$ & $<15$ \\
pH (as 20\% starch) & $4.59 \pm 0.072 *$ & $6.08 \pm 0.01$ & $4.5-8.0$ \\
Limit of iron, ppm & $<10$ & $<10$ & $<10$ \\
\hline
\end{tabular}

*Significant difference $(p<0.05)$ between starch samples.

The starch obtained from the yellow $M$. indica and $A$. heterophyllus seeds conformed with the criteria set by the USP for potato, wheat, tapioca, rice and corn starch, as presented in Table 3 . The starch samples turned dark blue in color due to the amyloseiodine complex formed after the addition of iodine-potassium iodide solution. LOD is a measure of the amount of water and volatile matter present in the sample at specified drying conditions, which affects the physical, chemical and microbiological properties of the excipient and finished product (Gerhardt, 2009). The LOD of starch samples displayed comparable results $(p=0.149)$ and met the USP specifications of official starches. The $\mathrm{pH}$ value $(p<$ 0.001 ) and limit of iron of the isolated starches were also within the limits set by the USP.

The quality control tests of the formulations are shown in Table 4. Uniformity of tablet weight and thickness are important parameters that indicate the amount of the active pharmaceutical ingredient present in the dosage form and ensure good packing of tablets (Nguwalka et al., 2010). Both tablets formulated using yellow $M$. indica and $A$. heterophyllus seed starch as binder and disintegrant displayed acceptable uniformity of tablet weight and did not deviate in the allowable 5\% difference in weight (USP, 2017), with yellow $M$. indica seed starch tablets showing significantly higher average weight compared to A. heterophyllus $(p<0.001)$. Thickness can vary with no change in weight because of the difference in the density of granulation and the pressure applied to the tablets, as well as the speed of tablet compression (Allen, 2013). This resulted in yellow $M$. indica seed starch tablets displaying significantly higher thickness in comparison to $A$. heterophyllus $(p<0.001)$.

Table 4: Quality control tests of paracetamol tablet formulation using starch from yellow $M$. indica and $A$. heterophyllus seeds as binder and disintegrant.

\begin{tabular}{lccc}
\hline Parameter & $\begin{array}{c}\text { Yellow M. indica } \\
\text { seed starch }\end{array}$ & $\begin{array}{c}\text { A. heterophyllus } \\
\text { seed starch }\end{array}$ & $\begin{array}{c}\text { Acceptance } \\
\text { criteria }\end{array}$ \\
\hline Average tablet weight, mg & $637.90 \pm 5.49^{*}$ & $620.80 \pm 5.53$ & $544-648$ \\
$\begin{array}{l}\text { Percent difference in } \\
\text { weight, \% }\end{array}$ & 0.86 & 0.89 & $5^{\mathrm{a}}$ \\
Thickness, mm & $5.24 \pm 0.041^{*}$ & $5.07 \pm 0.036$ & - \\
Hardness, kg & $4.10 \pm 0.21^{*}$ & $8.40 \pm 0.30$ & $4-10$ \\
Friability, \% & $0.68 \pm 0.025$ & $0.68 \pm 0.026$ & $\mathrm{nmt} 1.00^{\mathrm{a}}$ \\
Disintegration time, s & $66.67 \pm 15.2^{*}$ & $328.00 \pm 25.16$ & 1800 \\
Dissolution test (as Q), \% & $96.00 \pm 0.56$ & $95.69 \pm 0.33$ & $\mathrm{nlt} 80^{\mathrm{a}}$ \\
& $101.46 \pm 0.12^{*}$ & $97.15 \pm 1.64$ & nlt $90 \mathrm{but} \mathrm{nmt}$ \\
Assay, \% & & & $110^{\mathrm{a}}$ \\
\hline
\end{tabular}

* Significant difference $(p<0.05)$ between starch samples. ${ }^{a}$ Acceptance criteria based from the USP 40 Acetaminophen Tablets Monograph. Nmt - not more than, nlt - not less than.

Tablet hardness for both yellow $M$. indica and $A$. heterophyllus seed starch batches met the specification for uncoated tablets, with $A$. heterophyllus exhibiting significantly higher value than yellow $M$. indica $(p<0.001)$. For friability, yellow $M$. indica seed starch tablet batches showed comparable results with $A$. heterophyllus $(p=0.882)$ and conformed to the criteria specified in the USP (2017). These indicate that the produced tablets will be able to resist mechanical stress conditions such as coating, packaging, storage, transportation and further processing (Allen, 2013). These parameters also affect the disintegration time and dissolution rate of the tablets (Ansel et al., 1999).

Disintegration test is a measurement of the time required for the tablet to disintegrate into particles under a given set of conditions (Allen, 2013). While both batches contain the same amount of disintegrant, the yellow $M$. indica seed starch 
tablet batch exhibited significantly faster disintegration time as compared to A. heterophyllus $(p<0.001)$. High amylose content has been known to resist swelling and disintegration (Reddy et al., 1994). Nonetheless, the produced tablets passed the acceptance criteria for disintegration time.

The rate and extent of absorption, and therapeutic outcome of a drug is determined by the dissolution rate (Nguwalka et al., 2010). Dissolution is affected by the type and concentration of binder, hardness, solubility of the drug, manufacturing process and diluents. Drug release of tablets with yellow $M$. indica and $A$. heterophyllus seed starch conformed with the USP specification and displayed comparable Q values ( $p$ $=0.283$ ). The assay of acetaminophen (paracetamol) tablet using yellow $M$. indica and $A$. heterophyllus seed starch passed the allowable specifications (USP, 2017). The significant difference in the percentage potency between batches $(p=0.010)$ may be attributed to the differences in tablet weight, thickness, hardness and disintegration times.

\section{CONCLUSION}

This study investigated the physicochemical, binder and disintegrant properties of starch collected from yellow $M$. indica and A. heterophyllus seeds as potential excipients in paracetamol tablet formulation. The considerable differences in the physicochemical properties of starches were probably due to the distinctiveness of starch isolated from different sources. Although both starches demonstrated passable to poor flow properties, it conformed with the USP specifications for physicochemical properties of official starches, and quality control tests for acetaminophen (paracetamol) tablet. Thus, utilization of seeds from yellow $M$. indica and $A$. heterophyllus provides economically viable sources of starch for pharmaceutical use. Modifications in the extraction method can be conducted to improve flowability. Further study on the use of the yellow $M$. indica seed starch as superdisintegrant is also recommended, due to its fast disintegration at low concentration.

\section{ACKNOWLEDGMENTS}

This research was financially supported by the Philippine Institute of Traditional and Alternative Health Care (PITAHC).

\section{CONFLICT OF INTEREST}

The authors declare no conflict of interest.

\section{REFERENCES}

Achor M, Oyeniyi JY, Musa M, Gwarzo MS. Physicochemical properties of cassava starch retrograded in alcohol. J App Pharm Sci, 2015; 5(10):126-131.

Ahmad MZ, Akhter S, Ahmad I. In vitro and in vivo evaluation of Assiam Bora rice starch based bioadhesive microspheres as a drug carrier for colon targeted. Exp Opin Drug Delivery, 2012; 9:141-149.

Allen LV. 2013. Remington: The Science and Practice of Pharmacy. $22^{\text {nd }}$ edition. Philadelphia, Pennyslvania: University of the Sciences in Philadelphia.

Ansel H, Allen L, Popovich N. 1999. Disperse Systems. In Pharmaceutical Dosage Forms and Drug Delivery Systems. 7th edition. Baltimore, Maryland: Lippincott Williams \& Wilkins 203-208.

Aulton ME. 2017. Powder flow. Chapter 2. In: Aulton ME, Taylor KMG, eds. Aulton's Pharmaceutics E-book: The design and manufacture of medicines. 5th edition. China: Elvesier Ltd. 188-191.

Bromberg LE, Buxton DK, Friden PM. Novel periodontal drug delivery systems for the treatment of periodontitis. J Control Release, 2001; 75:93-102.

Builders PF, Arhewoh MI. Pharmaceutical applications of native starch in conventional drug delivery. Starch, 2016; 68:1-10.

Builders PF, Nnurum A, Mbah CC, Attama AA, Manek R. The physicochemical and binder properties of starch from Persea Americana Miller (Lauraceae). Starch, 2010; 62:309-320.

de Oliveira LA, de Souza-Moreira TM, Cefali LC, Chiari BG, Correa MA, Isaac VLB, Salgado HRN and Pietro RCLR. Design of antiseptic formulations containing extract of Plinia cauliflora. Braz J Pharm Sci, 2011; 47(3):525-533.

El Saadany RMA, Foda YH, Saadany FM. Studies on starch extracted from mango seeds (Mangifira indica) as a new source of starch Starch, 1980; Nr 4.32:S113-116.

Fuglie KO. Raw materials for starch in Asia: Some economic considerations. UPWARD Fieldnotes (Philippines), 1998; 7(2):5-7.

Gerhardt AH. Moisture effects on solid dosage forms formulation, processing, and stability. Journal of GXP Compliance, 2009; 13(1):58-66.

Hartesi B, Sriwidodo, Abdassah M., Chaerunisaa AY. Starch as pharmaceutical excipients. Int J Pharm Sci Rev Res, 2016; 41(2):59-64.

Hassan LG, Muhammad AB, Aliyu RU, Idris ZM, Izuagie T, Umar KJ, Sani NA. Extraction and characterization of starches from four varieties of Mangifera indica seeds. IOSR-JAC, 2013; 3(6):16-23.

Illum L, Fischer AN, Jabbal-Gill I, Davis SS. Bioadhesive starch microspheres and absorption enhancing agents act synergistically to enhance the nasal absorption of polypeptides. Int J Pharm, 2001; 222:109-119.

Krogars K, Antikainen O, Heinamaki J, Laitinen N, Yliruusi J. Tablet film-coating with amylose-rich maize starch. Eur J Pharm Sci, 2002; 17:23-30

Lahdenpää E, Niskanan M, Yliruusi J. Study of some essential physical characteristics of three Avicel $\mathrm{PH}$ grades using a mixture design Eur J Pharm Biopharm, 1996; 42(3):177-182.

Lin L, Cai C, Gilbert RG, Li E, Wang J, Wei C. Relationships between amylopectin molecular structures and functional properties of different-sized fractions of normal and high-amylose maize starches. Food Hydrocolloids, 2015; doi: 10.1016/j.foodhyd.2015.07.019.

Nguwalka, NC, Idiakhoa, BA, Ogaji, NI and Okafor, IS. Formulation and evaluation of paracetamol tablets manufactured using the dried fruit of Phoenix dactylifera Linn as an excipient. Research. In: Pharmaceutical Biotechnology, 2010; 2(3):25-32.

Ochubiojo EM, Rodrigues A. 2012. Starch: from food to medicine. In: Valdez B, ed. Scientific, health and social aspects of the food industry. Rijeka, Croatia:InTech 357-358.

Pathak PD, Mandavgane SA, Kulkarni BD. Fruit peel waste as a novel low-cost bio adsorbent. Rev Chem Eng, 2015; 31(4):361-381.

Philippine Statistics Authority. 2015. Supply utilization accounts (SUA) of selected agricultural commodities 2012-2014. [ONLINE] Available at https://psa.gov.ph/sites/default/files/sua_12-14.pdf. [Accessed 31 May 2017].

Rajeevkumar P, Rajeev R, Anikumar N. Studies on Curcuma angustifolia starch as a pharmaceutical excipient. Int J PharmTech Res, 2010; 2(4):2456-2460.

Reddy KR, Subramanian R, Ali SZ, Bhattacharya KR. Viscoelastic properties of rice-flour pastes and their relationship to amylose content and rice quality. Cereal Chem, 1994; 71(16):548-552.

Seville JPK, Tüzün U, Clift R. 1997. Particle mechanics. In: Processing of particulate solids. Powder Technology Series. $2^{\text {nd }}$ edition. London, UK: Chapman \& Hall 99-144.

Shah RB, Tawakkul MA, Khan MA. Comparative evaluation of flow for pharmaceutical powders and granules. AAPS PharmSciTech, 2008; 9(1):250-258

Singh N, Singh J, Kaur L, Sodhi NS, Gill BS. Morphological, 
thermal and rheological properties of starches from different botanical sources. Food Chemistry, 2003; 81:219-231.

Tulyathan V, Tananuwong K, Songjinda P, Jaiboon N. Some physicochemical properties of jackfruit (Artocarpus heterophyllus Lam) seed flour and starch. ScienceAsia, 2002; 28:37-41.

Tziotis A, Seetharaman K, Klucinec JD, Keeling P, White PJ. Functional properties of starch from normal and mutant corn genotypes. Carbohydr Polym, 2005; 61:238-247.

United States Pharmacopeia 40-National Formulary 35 (USP 40-NF 35). 2017. Maryland, USA: The United States Pharmacopeial Convention.

Walter WM Jr, Truong VD, Weisenborn DP, Carvajal P. Rheological and physicochemical properties of starches from moist- and dry-type sweet potatoes. J Agric Food Chem, 2000; 48:2937-2942.
Wang JP, Li Y, Tian YQ, Xu XM, Ji XX, Cao X, Jin ZY. A novel triple-wavelength colorimetric method for measuring amylose and amylopectin contents. Starch, 2010; 62(10):508-516.

How to cite this article:

Manalo RAM, Arollado EC, Pellazar JMM, Siocson MPF, Ramirez R-LF. Yellow Mangifera indica Linn. and Artocarpus heterophyllus Lam. seed starch as binder and disintegrant in paracetamol tablet formulation. J App Pharm Sci, 2018; 8(03): 060-066. 